\title{
PERCEPÇÃO DE LICENCIANDOS SOBRE O PAPEL DA EXPERIMENTAÇÃO NO ENSINO DE QUÍMICA
}

\section{PERCEPTION OF GRADUATES ON THE ROLE OF EXPERIMENTATION IN CHIMESTRY TEACHING}

\author{
Paula Cavalcante Monteiro ${ }^{1}$ \\ Maria Aparecida Rodrigues ${ }^{2}$ \\ Ourides Santin Filho ${ }^{3}$ \\ Michel Corci Batista ${ }^{4}$
}

\begin{abstract}
Resumo: Estudos na área têm apontado que é fundamental fazer com que os alunos construam seus conhecimentos. Contudo, os experimentos de laboratório normalmente executados por eles não apresentam caráter investigativo, constituindo-se apenas em mera repetição de roteiros prontos. Neste trabalho, apresentamos e analisamos as percepções de seis alunos do curso de Licenciatura em Química da Universidade Estadual de Maringá (UEM) sobre o papel das atividades experimentais no Ensino de Química (EQ). A abordagem da pesquisa é de natureza qualitativa e os dados foram coletados por meio de um questionário semiestruturado, com a finalidade de investigar os conhecimentos prévios dos licenciandos sobre aspectos importantes relacionados à experimentação no EQ. O teor das respostas apresentadas no respectivo questionário foi interpretado por meio da Análise Textual Discursiva (ATD). Os resultados permitem concluir que os licenciandos possuem uma visão empírico indutivista, percebendo o experimento como atividade de comprovação de teorias.
\end{abstract}

Palavras-chave: Ensino de química; Formação inicial; Experimentação

Abstract: Studies in the area have demonstrated that it is essential to make students build their own knowledge. However, laboratory experiments normally performed by them do not have an investigative character, constituting a mere repetition of ready-made scripts. In this work, we present and analyze the perceptions of six students in the Chemistry degree course from the State University of Maringá (UEM) about the role of experimental activities in Chemistry Education (CE). The research approach has a qualitative nature. The results allow us to conclude that the graduates have an empirical inductive view, perceiving the experiment as a theory-proofing activity.

Keywords: Chemical Education; Initial Formation; Experimentation.

\footnotetext{
${ }^{1}$ Doutora em Ensino de Ciências pela Universidade Estadual de Maringá. Professora Adjunta da Universidade Tecnológica Federal do Paraná, Campus Campo Mourão, Campo Mourão, PR, Brasil. Email: paulacavalcantemonteiro@gmail.com

${ }^{2}$ Doutora em Química pela Universidade Estadual de Campinas. Professora Associada da Universidade Estadual de Maringá, Maringá, PR, Brasil. E-mail: aparecidar@gmail.com

${ }^{3}$ Doutor em Ciências pela Universidade de São Paulo. Professor Associado da Universidade Estadual de Maringá, PR, Brasil. E-mail: osantin@uem.br

${ }^{4}$ Doutor em Ensino de Ciências pela Universidade Estadual de Maringá, Professor Adjunto da Universidade Tecnológica Federal do Paraná, Campus Campo Mourão, Campo Mourão, PR, Brasil. E-mail: michel@utfpr.edu.br
} 


\section{Introdução}

A experimentação no ensino de ciências tem sido objeto de muitos estudos, em especial na última década. No ensino superior de Química, mais especificamente nos cursos de formação de professores, a experimentação também tem recebido destaque, conforme indicam alguns estudos (GALIAZZI; GONÇALVES, 2004; GONDIM; MÓL, 2007; LÔBO, 2012; SUART; AFONSO, 2015).

Uma pesquisa conduzida por Queiroz et al. (2017) sobre as dissertações e teses defendidas no Brasil no período de 2004 a 2013 e que se referem à formação inicial de professores de química, identificou vários trabalhos com ênfase na experimentação. Os autores (p. 1895) destacam que existe

[...] preocupação da comunidade acadêmica em promover a apropriação por parte dos licenciandos de um entendimento a respeito da experimentação que ultrapasse visões simplistas sobre a natureza da ciência.

Concordamos com os referidos autores quanto a necessidade de se desenvolver metodologias e estratégias que motivem aos estudantes a construção do conhecimento. Isso só será viável se for oportunizado aos futuros professores possibilidades de vivenciarem, de maneira crítica, tais questões. Nosso trabalho objetivou analisar as percepções $^{5}$ de alunos do segundo ano do curso de Licenciatura em Química da Universidade Estadual de Maringá, sobre o papel das atividades experimentais no Ensino de Química (EQ).

\subsection{Fundamentação teórica}

Há um consenso entre os professores de ciências de que as aulas experimentais são uma maneira muito eficiente de melhorar o entendimento de conteúdos científicos e facilitar a aprendizagem, sendo concebidas como um poderoso recurso didático. No

\footnotetext{
${ }^{5}$ Adotamos neste trabalho o termo percepção, que segundo a definição do dicionário online Aurélio: Ação ou efeito de perceber, de compreender o sentido de algo por meio das sensações ou da inteligência: percepção do sofrimento, do clima. Avaliação sobre coisas ou seres a partir de um julgamento ou opinião. PERCEPÇÃO. In: DICIO, Dicionário Online de Português. Porto: 7Graus, 2020. Disponível em: https://www.dicio.com.br/percepcao/ . Acesso em: 06/04/2020.
} 


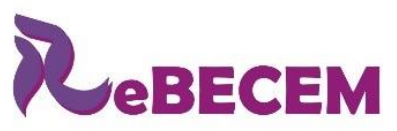

\section{Revista Brasileira de Educação em \\ Ciências e Educação Matemática}

DOI: https://doi.org/10.33238/ReBECEM.2021.v.5.n.1.25879

entanto, no EQ, as aulas experimentais, sejam no ensino básico ou nas disciplinas iniciais da graduação, têm sido desenvolvidas pela maioria dos professores com a intenção de comprovar uma teoria ou como mero instrumento motivador para a aprendizagem (LÔBO, 2012). É importante destacar também que os experimentos propostos pelos professores nem sempre apresentam objetivos claros para os alunos, pois eles são orientados a reproduzir um roteiro detalhado e definido, e cujo resultado já é conhecido.

Em geral, duas visões são comuns entre os professores: a de que a função da experimentação é comprovar uma teoria e a de que, a partir de um experimento, os alunos, por descoberta, conseguem chegar a um entendimento do tema em questão. O tipo de abordagem a ser desenvolvida em sala de aula depende diretamente das convicções daquele que leciona, bem como de sua formação anterior (MEDEIROS; BEZERRA FILHO, 2000), ou seja, se o professor acredita que os experimentos comprovam teorias, será exatamente assim que ele ensinará aos seus alunos.

As atividades mecânicas, como por exemplo repetir o experimento várias vezes, anotando dados em tabelas para que posteriormente se construa gráficos, não proporcionam ao aluno a oportunidade de refletir sobre o experimento. "Os alunos têm dificuldade de perceber o que realmente importa nas medidas que estão sendo tomadas e o que poderia ser descartado" (CAMILLO; MATTOS, 2014, p. 129). No desenvolvimento de atividades experimentais no EQ, Suart (2014, p. 72) argumenta que:

[...] tais atividades são, geralmente, realizadas de forma isolada do contexto de ensino, utilizadas após o desenvolvimento de determinado conteúdo em sala de aula, a fim de que o aluno verifique ou comprove o que foi discutido. [...] Desta forma, pouca ou nenhuma discussão sobre os dados e resultados obtidos, bem como suas implicações, são realizadas.

Os roteiros do tipo "receita de bolo", geralmente seguidos durante as aulas experimentais, estão baseados numa visão empirista-indutivista, "nesta concepção o conhecimento científico é obtido daquilo que se observa, pois, a observação é a fonte e a função do conhecimento, por meio da aplicação do método científico" (ROSITO, 2000, p. 200). A respeito dessa visão de Ciência, Silva e Zanon (2000, p. 121) ressaltam que:

A prevalência desta visão de que a ciência 'está na realidade, à espera de ser descoberta' é um indício de que o empiricismo-indutivismo é amplamente dominante, nos contextos das escolas, em detrimento da valoração da capacidade criadora do sujeito que se transforma ao transformar/criar o real colocado em discussão. 


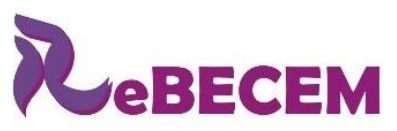

Revista Brasileira de Educação em

Ciências e Educação Matemática

DOI: https://doi.org/10.33238/ReBECEM.2021.v.5.n.1.25879

Muitas vezes, mesmo seguindo os passos descritos nos roteiros, o experimento não produz o resultado esperado. A explicação para este fato costuma recair sobre a falta de destreza no manuseio dos instrumentos de laboratório, a erros no preparo de soluções ou mesmo à baixa qualidade dos reagentes, assim, o erro não é valorizado. Conforme destaca Suart (2014, p. 72), "os erros são tidos como um fator negativo, como se o experimento tivesse sempre que dar certo, ou seja, como se a Ciência nunca errasse".

Por outro lado, a experimentação investigativa (EI) contrapõe-se à experimentação tradicionalista. Sobre isso, vários autores (SUART, 2014; KASSEBOEHMER et al., 2015; CARVALHO, 2013) defendem a EI pois, numa aula experimental, não basta que o aluno manipule vidrarias e reagentes ou prepare soluções, ele precisa antes de tudo manipular ideias (problemas, dados, teorias, hipóteses, argumentos). "O aluno deve ser engajado não apenas num trabalho prático, manual, mas principalmente intelectual" (SOUZA et al., 2013, p. 13), isto é, é necessário integrar a ação com a reflexão.

Dentro dessa perspectiva, experimentos conduzidos de forma investigativa podem possibilitar a compreensão da natureza da ciência e dos seus conceitos, bem como auxiliar no desenvolvimento de atitudes científicas, contribuindo para despertar o interesse pela Ciência. Isto porque, em atividades experimentais com essa abordagem, o aluno é colocado frente às situações-problema adequadas que vão propiciar uma construção de conhecimento (FERREIRA; HARTWIG; OLIVEIRA, 2010). Nesse processo, o aluno possui um papel ativo em sua aprendizagem e cabe ao professor orientá-lo na busca de soluções para o problema.

Um trabalho que merece destaque quando se trata de experimentação no ensino é o de Gonçalves e Marques (2006), intitulado: “Contribuições pedagógicas e epistemológicas em textos de experimentação no ensino de química". O trabalho teve como objetivo problematizar a experimentação na formação inicial de professores de Química. Assim, os autores analisaram 38 artigos publicados no período de 1995 a 2003, da seção "Experimentação no Ensino de Química" da Revista Química Nova na Escola (QNEsc), com a intenção de compreender as características dos discursos sobre as atividades experimentais contidas nos respectivos textos. Dos resultados da análise realizada surgiram seis categorias: 1 . Crença na motivação; 2. Dimensão epistemológica da experimentação no ensino; 3. Contexto dialógico; 4. Condições materiais: o alicerce no alternativo; 5. Conteúdos: para além do conceitual; 6. Conteúdos: mostrar a relevância do que se aprende. Assim, para esses pesquisadores (p. 235): 
[..] é preciso refletir acerca dos entendimentos sobre a natureza epistemológica da experimentação de tal modo que a realização de atividades experimentais contribua para enriquecer o conhecimento discente a respeito do papel da experimentação na produção do conhecimento científico.

Concordamos com Gonçalves e Marques (2006), sobre a relevância de se entender a natureza epistemológica da experimentação, uma vez que tal entendimento vai favorecer a compreensão do aluno acerca do papel do experimento na produção de conhecimento. Para haver uma mudança significativa na concepção dos professores sobre o papel da experimentação, entendemos que é preciso discutir a experimentação sobre o ponto de vista epistemológico nos cursos de licenciatura das áreas de Ciências da Natureza.

\section{Materiais e métodos}

Destacamos que esse estudo é parte de uma pesquisa mais ampla e realizada no contexto de um trabalho de doutorado desenvolvida com seis licenciandos em Química, matriculados na disciplina de Instrumentação para o Ensino de Química I, da UEM Campus Maringá no Paraná, no segundo semestre de 2016. Contudo, o presente trabalho pode ser reproduzido por outros pesquisadores, pois apresentamos aqui, como já afirmado, apenas a análise de um questionário que investigou a percepção dos alunos sobre a experimentação no ensino.

Os dados foram coletados no contexto de um curso de extensão intitulado " $\mathrm{O}$ papel da experimentação no ensino de Química", enfatizando a experimentação investigativa. O curso teve o intuito de oportunizar aos acadêmicos do curso de Química Licenciatura uma reflexão sobre o ensino por investigação e a experimentação investigativa no EQ. Ele teve duração de trinta horas e foi desenvolvido no período de 11 de julho a 11 de outubro de 2016, no contra turno das aulas, no período vespertino, totalizando dez encontros, com três horas cada.

Ressaltamos que a participação dos licenciandos foi voluntária. Nesse sentido, os participantes da pesquisa tiveram conhecimento prévio de todos os procedimentos que seriam seguidos durante a realização do curso de extensão. Estando todos os critérios devidamente esclarecidos, os mesmos assinaram um termo de consentimento, autorizado 
DOI: https://doi.org/10.33238/ReBECEM.2021.v.5.n.1.25879

pelo comitê de ética em pesquisa (COPEP-UEM), via parecer $\mathrm{n}^{\mathbf{0}}$ CAAE 57169316.1.0000.0104. No intuito de respeitar os licenciandos e preservar-lhes as referidas identidades, os mesmos foram aqui denominados por L1, L2, L3, L4, L5 e L6.

$\mathrm{Na}$ realização desse trabalho, optamos por uma metodologia de pesquisa qualitativa, por não se quantificar com dados matemáticos, mas sim com a subjetividade. A referida abordagem, “[...] aprofunda-se no mundo dos significados das ações e relações humanas, um lado não perceptível e não captável em equações, médias e estatísticas" (MINAYO, 1994, p. 22).

O tema Experimentação Investigativa foi tratado e demandado em diversas etapas, compreendendo visitas a laboratórios de pós-graduação, leitura e discussão de textos, desenvolvimento de experimentos e comparação de roteiros experimentais tradicional e investigativo. Foram conduzidos diversos encontros, devidamente registrados mediante gravação em áudio e posterior transcrição na íntegra, a fim de possibilitar uma análise mais minuciosa dos dados. Outros instrumentos como questionários, observações e notas de campo também foram adotados no processo de coleta de informações.

Neste trabalho foram utilizados apenas os dados coletados por meio do questionário inicial, cuja finalidade era a de investigar as percepções dos participantes sobre o papel das atividades experimentais no EQ.

Acreditamos ser fundamental compreender a percepção que um aluno da licenciatura tem sobre o papel da atividade experimental no EQ e, posteriormente, entender como esta influencia a formação desse futuro professor.

Na análise dos dados coletados, utilizamos a Análise Textual Discursiva (ATD). Trata-se de uma abordagem de análise que transita entre duas formas consagradas de análise na pesquisa qualitativa: a análise de conteúdo e a análise do discurso (MORAES; GALIAZZI, 2006, p. 118). Esse processo de análise se dá em cinco etapas: a preparação das informações; a transformação do conteúdo em unidades (unitarização); a classificação das unidades em categorias (categorização); sua descrição e interpretação.

\section{Resultados e discussão}

Inicialmente, os licenciandos realizaram uma visita aos laboratórios de pesquisa do Departamento de Química da instituição na qual são alunos. Durante aquela visita, eles tiveram a oportunidade de conversar com pesquisadores, tanto iniciantes quanto mais 


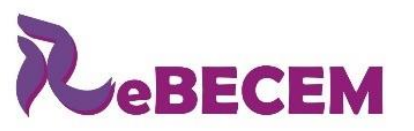

\section{Revista Brasileira de Educação em \\ Ciências e Educação Matemática}

DOI: https://doi.org/10.33238/ReBECEM.2021.v.5.n.1.25879

experientes, sobre as atividades desenvolvidas naquele ambiente. Posteriormente à visita, cada licenciando elaborou um diário de campo, com aspectos mais relevantes do ambiente visitado, bem como respondeu, individualmente e por escrito, um questionário com a finalidade de averiguar suas percepções a respeito de questões relacionadas à experimentação para o EQ. O questionário está representado no Quadro 1.

\begin{tabular}{|l|l|}
\hline Questão 1 & Qual o papel do experimento no Ensino de Química? \\
\hline Questão 2 & Como que você acha que devem ser as atividades experimentais nas aulas de Química? \\
\hline Questão 3 & $\begin{array}{l}\text { Para desenvolver experimentos com vistas a ensinar conceitos químicos } \\
\text { precisamos percorrer os mesmos caminhos dos cientistas? Justifique. }\end{array}$ \\
\hline Questão 4 & $\begin{array}{l}\text { Quais os elementos (etapas) que você julga importantes para a construção de } \\
\text { uma atividade experimental? }\end{array}$ \\
\hline Questão 5 & $\begin{array}{l}\text { Como você acha que podemos reelaborar um procedimento experimental clássico } \\
\text { (baseado em um roteiro) em um procedimento com caráter investigativo? }\end{array}$ \\
\hline
\end{tabular}

Quadro 1: Questionário aplicado aos licenciandos

Fonte: Elaborado pelos autores.

A partir das respostas dadas à questão 1, que abordava o papel do experimento no EQ, foi possível estabelecer duas categorias, a saber: 1.1) Caráter comprobatório ou demonstrativo de uma teoria; 1.2) Ponto de partida para construção do conhecimento. Excertos das respostas nas referidas categorias estão organizadas nos quadros de 2 e 3 .

\begin{tabular}{|l|l|}
\hline Sujeitos & Excertos \\
\hline L2 & o papel é comprovar as teorias que aprendemos nos livros didáticos. \\
\hline L4 & ensinar o que já é teoricamente comprovado, [...]. \\
\hline L5 & $\begin{array}{l}\text { experimento tem como papel de ensinar a manusear e demonstrar o porquê e como } \\
\text { acontece. }\end{array}$ \\
\hline L6 & {$[\ldots]$ explicar com as teorias conhecidas e por final demonstrar como funciona a teoria. } \\
\hline
\end{tabular}

Quadro 2 - Categoria 1.1: experimento como caráter comprobatório ou demonstrativo de uma teoria.

Fonte: Elaborado pelos autores.

Observamos nos fragmentos de respostas que os referidos quatro licenciandos ainda continuaram apresentando percepções que nos remetem a uma visão empirista ou reducionista de ciência. Essa crença de que a atividade experimental tem o poder de comprovar a teoria pode ser influência de uma visão dogmática de ciência promovida por professores durante a formação construída no Ensino Médio (GALIAZZI; GONÇALVEZ, 2004). Visões inadequadas, de que a prática serve para comprovar a teoria, bem como todo o conhecimento produzido pela Ciência é verdadeiro e inquestionável, convergem para as ideias de Cachapuz, et al., (2005) sobre as possíveis visões deformadas da ciência, ou seja a visão empírico-indutivista ligada à ideia de 
DOI: https://doi.org/10.33238/ReBECEM.2021.v.5.n.1.25879

"descobertas" e a visão rígida que percebe o método científico como uma sequência de etapas a serem seguidas.

Quanto ao conhecimento fundamentado no senso comum, apresentado pelos licenciandos sobre o papel da experimentação no ensino, Suart (2014, p. 82) comenta que:

[...], muitas dessas concepções estão enraizadas em pressupostos empiristas e indutivistas, os quais não valorizam características próprias das investigações científicas, como formulação de problemas, proposição de hipóteses e desenvolvimento de procedimentos.

\begin{tabular}{|l|l|}
\hline Sujeitos & Excertos \\
\hline L1 & {$[\ldots]$ a partir do experimento o aluno deve começar a construir o conhecimento. } \\
\hline L3 & {$[\ldots]$ a finalidade de auxiliar o processo de construção do conhecimento do aluno. } \\
\hline
\end{tabular}

Quadro 3: Categoria 1.2: experimento como ponto de partida para construção do conhecimento.

Fonte: Elaborado pelos autores.

Em um primeiro momento, percebemos que os dois licenciandos destacados entenderam que o experimento tem o papel de contribuir no processo de construção do conhecimento. Isso demonstra um conhecimento mais elaborado acerca do ensino de Ciências, pois apresenta a ideia de que o experimento não tem um fim em si mesmo, mas sim um papel pedagógico no ensino (GALIAZZI; GONÇALVES, 2004).

$\mathrm{Na}$ Questão 2, os licenciandos foram questionados a respeito de como deveriam ser as atividades experimentais nas aulas de Química. A partir da análise de suas respostas foram estabelecidas seis categorias: 2.1) Visão utilitarista das atividades experimentais; 2.2) Explicar um fenômeno estudado; 2.3) Não deve demonstrar uma teoria; 2.4) Deve preceder uma teoria; 2.5) Deve ser relacionada ao cotidiano dos alunos; 2.6) Deve ter material de apoio. Excertos das respostas aparecem nos próximos seis quadros na sequência.

\begin{tabular}{|l|l|}
\hline Sujeitos & Excertos \\
\hline L5 & {$[\ldots]$ para saber que tal atividade experimental serve para fazer o que e quando. } \\
\hline
\end{tabular}

Fonte: Elaborado pelos autores.

$\mathrm{O}$ argumento desse licenciando evocou a ideia de a Ciência ter caráter utilitarista, devendo "servir para alguma coisa". Acreditamos que tal percepção pode ser influência da educação científica do estudante repassada no ensino médio (OLEQUES, et al., 2013).

\begin{tabular}{|l|l|}
\hline Sujeitos & Excertos \\
\hline L6 & {$[\ldots]$ consiga ter conclusões sobre o que está acontecendo e porque aconteceu isso. } \\
\hline
\end{tabular}


DOI: https://doi.org/10.33238/ReBECEM.2021.v.5.n.1.25879

Quadro 5: Categoria 2.2 - Explicar um fenômeno estudado.

Fonte: Elaborado pelos autores.

Percebemos no excerto que o licenciando demonstrou entender, por meio do experimento, que se pode concluir algo sobre o fenômeno em questão, bem como o mesmo estar relacionado à ilustração de um conceito. Portanto, o experimento tem a função de comprovar a teoria (SILVA; ZANON, 2000).

\begin{tabular}{|l|l|}
\hline Sujeitos & Excertos \\
\hline L3 & $\begin{array}{l}{[\ldots] \text {. O experimento não deve ser realizado apenas como forma de demonstrar que aquilo }} \\
\text { que está na literatura é verdadeiro. }\end{array}$ \\
\hline
\end{tabular}
Quadro 6: Categoria 2.3 - Não deve demonstrar uma teoria.

Fonte: Elaborado pelos autores.

Notamos que o licenciando L3, como já discutido na categoria 2.1, parece ter uma compreensão de Ciência que se distancia de ideias empiristas/indutivistas, ou seja, o licenciando não vê o experimento com função de comprovar a teoria.

\begin{tabular}{|l|l|}
\hline Sujeitos & Excertos \\
\hline L1 & Os experimentos devem preceder a teoria. \\
\hline
\end{tabular}

Quadro 7: Categoria 2.4 - Deve preceder uma teoria.

Fonte: Elaborado pelos autores.

O licenciando manifestou em seu exposto uma percepção baconiana, empirista: o conhecimento começa com a observação. Na verdade, seria o contrário. De acordo com Wellington (1998, apud GALIAZZI; GONÇALVES, 2004, p. 327), os experimentos dependentes de alguma teoria, "não são realizados no "vácuo teórico", isto é, as predições, observações e inferências são sempre originadas a partir de uma teoria".

\begin{tabular}{|l|l|}
\hline Sujeitos & Excertos \\
\hline L2 & {$[\ldots]$ devem ocorrer com mais frequências, e relacionados com o cotidiano das pessoas [...]. } \\
\hline
\end{tabular}
Quadro 8: Categoria 2.5 - Deve ser relacionado ao cotidiano dos alunos.

Fonte: Elaborado pelos autores.

$\mathrm{O}$ fragmento em destaque mostra uma crítica à falta de experimentos no Ensino de Química, principalmente no EM. Em geral, os professores trabalham mais teoria e quase não realizam experimentos, sejam no laboratório ou na sala de aula. Quanto aos experimentos estarem relacionados ao cotidiano, faz sentido o argumento do licenciando, pois quanto mais próximos do cotidiano do aluno estiverem os temas trabalhados na escola, mais fácil será para o mesmo aplicar o conhecimento aprendido (ECHEVERRÍA; POZO, 1998). 
DOI: https://doi.org/10.33238/ReBECEM.2021.v.5.n.1.25879

\begin{tabular}{|l|l|}
\hline Sujeitos & Excertos \\
\hline L4 & Deveria sim ter uma apostila no intuito de orientar os alunos, [...]. \\
\hline
\end{tabular}

Quadro 9: Categoria 2.6 - Deve ter material de apoio.

Fonte: Elaborado pelos autores.

Podemos entender que o licenciando L4 valorizou o roteiro como guia ou orientação para os estudantes no desenvolvimento de um experimento. Sua percepção de experimentação implicou em seguir um método definido, seguir uma "receita de bolo".

Perguntamos aos licenciandos, na questão 3, se para desenvolver experimentos com vistas a ensinar conceitos químicos seria preciso percorrer os mesmos caminhos dos cientistas. Eles deveriam justificar a resposta. Suas respostas sugeriram o estabelecimento de três categorias: 3.1) Não, porque a escola só ensina conceitos consolidados; 3.2) Não, porque na escola o experimento deve ser mais simples; 3.3) Sim, porque os experimentos devem partir de uma problematização. As referidas categorias estão organizadas com seus respectivos excertos nos quadros a seguir.

\begin{tabular}{|l|l|}
\hline Sujeitos & Excertos \\
\hline L2 & $\begin{array}{l}\text { eu acho que não, [...] os conceitos químicos já estão determinados ou consolidados, para } \\
\text { ensinar aos alunos não é necessário o desenvolvimento de novos experimentos para provar } \\
\text { algo, que já está pronto. }\end{array}$ \\
\hline L3 & não, [...] o objetivo é apenas de levar conhecimento já consolidados aos alunos. \\
\hline L5 & $\begin{array}{l}\text { não, porque algo que irá abordar já terá um estudo detalhado por trás, as ideias, só serão } \\
\text { ensinadas se for consolidada. }\end{array}$ \\
\hline
\end{tabular}

Fonte: Elaborado pelos autores.

Identificamos nos fragmentos de respostas desses três licenciandos, a noção de que na escola se discute apenas conhecimentos já consolidados. Isso mostra que o espaço escolar vem sendo um local apenas de reprodução de ideias contidas em livros, sem que haja um debate maior sobre o que ainda está por ser conhecido/produzido. De posse dessa noção, ao estudante acaba sobrando a ideia de uma ciência já consolidada e imutável.

\begin{tabular}{|l|l|}
\hline Sujeitos & Excertos \\
\hline L4 & $\begin{array}{l}\text { não, por ser voltado ao ensino, sem nenhum fim de inovação, aplicar experimentos } \\
\text { considerados mais simples seria uma maneira mais fácil de analisar e compreender } \\
\text { determinado conteúdo. }\end{array}$ \\
\hline L6 & $\begin{array}{l}\text { não é preciso, pois o professor pode simplesmente explicar e falar os conceitos químicos. } \\
\text { Porém para um melhor entendimento e aproveitamento do conteúdo e da experimentação } \\
\text { seria melhor que os alunos seguissem os mesmos caminhos dos cientistas, [...]. }\end{array}$ \\
\hline
\end{tabular}

Quadro 11: Categoria 3.2 - Não, porque na escola o experimento deve ser mais simples.

Fonte: Elaborado pelos autores.

A resposta de L4 nos pareceu bastante consistente. Não se espera do ensino uma atividade de "inovação científica", mas da difusão de um conhecimento já consolidado. Isso significa que pode haver inovações na maneira de ensinar. Novas pedagogias devem 
DOI: https://doi.org/10.33238/ReBECEM.2021.v.5.n.1.25879

ser desenvolvidas para superar um modelo já sabidamente falido de escola. Embora o licenciando L6 ter afirmado não ser preciso seguir os mesmos caminhos dos cientistas, o mesmo deixa evidente que basta a aula expositiva, na forma como a atividade experimental é abordada na escola. Contudo, se a aula for experimental e a intenção do professor é obter maior aproveitamento, seria melhor o professor seguir os mesmos caminhos dos cientistas. Os licenciandos L4 e L6 expressaram que o compromisso maior da escola é com a compreensão dos alunos pelos conteúdos científicos e, para cumprimento dessa finalidade, as aulas expositivas dariam conta.

Os participantes L4 e L6 não deixaram claro o que seria "seguir os mesmos caminhos dos cientistas", mas inferimos que eles apontaram a necessidade de se fugir do modelo clássico de atividade experimental, com um roteiro estilo "receita de bolo", a ser seguido por si só.

\begin{tabular}{|l|l|}
\hline Sujeitos & Excertos \\
\hline L1 & $\begin{array}{l}\text { sim, pois a construção do experimento deve partir de uma problematização e a partir } \\
\text { daí realizar uma investigação. }\end{array}$ \\
\hline
\end{tabular}

Quadro 12 - Categoria 3.3: Sim, porque os experimentos devem partir de uma problematização. Fonte: Elaborado pelos autores.

Interessante notar que, dos seis licenciandos, só L1 afirmou a necessidade de se aproximar dos caminhos dos cientistas ao se desenvolver um experimento para ensinar conceitos. Também salientou a necessidade de se partir de uma problematização e, em seguida, proceder uma investigação.

Na questão de número 4, foi perguntado quais etapas eles julgariam importantes para a construção de uma atividade experimental. As respostas possibilitaram a identificação de três categorias, a saber: 4.1) Deve partir dos conhecimentos prévios dos alunos; 4.2) Deve iniciar pela observação; 4.3) Deve ter objetivo. As referidas categorias estão organizadas nos quadros de números 13 a 15.

\begin{tabular}{|l|l|}
\hline Sujeitos & Excertos \\
\hline L2 & pré-teoria ou conhecimento prévio do assunto [...]. \\
\hline L3 & $\begin{array}{l}\text { [...] breve fundamentação teórica pois o aluno deve possuir conhecimento prévio sobre o } \\
\text { assunto estudado. [...]. }\end{array}$ \\
\hline L4 & $\begin{array}{l}\text { Inicialmente ter conhecimento sobre o assunto, o que é, e para que serve: ter um } \\
\text { conhecimento prévio antes de realizar o experimento, [...]. }\end{array}$ \\
\hline L6 & $\begin{array}{l}\text { Para uma boa construção de uma de uma atividade experimental é preciso que ocorra } \\
\text { umomento de questionamentos e discussões sobre o que os alunos sabem do conteúdo e } \\
\text { então há o momento de realização do experimento [...]. }\end{array}$ \\
\hline
\end{tabular}

Quadro 13: Categoria 4.1 - Deve partir dos conhecimentos prévios dos alunos.

Fonte: Elaborado pelos autores. 


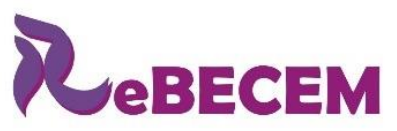

Revista Brasileira de Educação em

Ciências e Educação Matemática

DOI: https://doi.org/10.33238/ReBECEM.2021.v.5.n.1.25879

Identificamos que os licenciandos L2, L3, L4 e L6 consideraram importante partir dos conhecimentos prévios do aluno para o desenvolvimento de um experimento. A valorização dos conhecimentos prévios dos alunos é defendida por vários autores, dentre eles, destacamos (HODSON, 1988; POZO; CRESPO, 1998; AZEVEDO, 2013), isso porque atividades educativas capazes de promover aprendizagem devem iniciar pelos conhecimentos que o aluno já possui.

Em contrapartida às respostas acima, L1 entende que o experimento deve começar com a observação, conforme o quadro 14.

\begin{tabular}{|l|l|}
\hline Sujeitos & Excertos \\
\hline L1 & realização do experimento (observação), [...]. \\
\hline
\end{tabular}

Quadro 14: Categoria 4.2 - Deve iniciar pela observação.

Fonte: Elaborado pelos autores.

Trata-se de uma percepção empirista ingênua, surgida no século XVII com Francis Bacon, mas que ainda permeia o imaginário da sociedade. Tal linha de pensamento tem sido confirmada em resultados de pesquisas com professores e alunos (MEDEIROS; BEZERRA FILHO, 2000).

\begin{tabular}{|l|l|}
\hline Sujeitos & Excertos \\
\hline L5 & $1^{\circ}$ objetivo (quer ensinar o quê?) \\
\hline
\end{tabular}

Quadro 15: Categoria 4.3 - Deve ter objetivo.

Fonte: Elaborado pelos autores.

Concordamos com o licenciando L5 no tocante ao professor precisar ter um objetivo claro sobre o experimento a se desenvolver com os alunos, mesmo porque o experimento deve ter, sim, uma função pedagógica no ensino. Sobre essa questão, Borges (2002) afirma que os professores necessitam realizar experimentos com fins pedagógicos, sabendo diferenciá-los dos experimentos realizados pelos cientistas.

Em relação à questão 5, foi solicitado o que poderia ser feito para se transformar um procedimento experimental clássico (baseado em um roteiro do tipo "receita de bolo") em um procedimento com caráter investigativo. Nas respostas dadas pelos licenciandos, estabelecemos três categorias: 5.1) Criar uma problematização; 5.2) Mudando a quantidade dos reagentes; 5.3) Reproduzindo o experimento sem o procedimento. Os quadros de números 16 a 18 mostram as respectivas categorias e seus excertos.

\begin{tabular}{|l|l|}
\hline Sujeitos & Excertos \\
\hline L1 & {$[\ldots]$. Elaborar uma nova problematização. } \\
\hline
\end{tabular}


DOI: https://doi.org/10.33238/ReBECEM.2021.v.5.n.1.25879

\begin{tabular}{|l|l|}
\hline L3 & $\begin{array}{l}{[\ldots], \text { levantar questões problemas e levantar discussões sobre o que está acontecendo em }} \\
\text { determinado momento. }\end{array}$ \\
\hline L5 & $\begin{array}{l}\text { Primeiramente abordar um problema, com isso buscar os objetivos. Em segundo abrir um } \\
\text { questionamento para chegar no procedimento, [...]. }\end{array}$ \\
\hline
\end{tabular}

Quadro 16: Categoria 5.1 - Criar uma problematização.

Fonte: Elaborado pelos autores.

Nos fragmentos de respostas de três (L1, L3 e L5) dentre os seis licenciandos, observamos a afirmação de que uma boa maneira de dar um caráter investigativo ao experimento seria pensar em uma problematização. Suas respostas denotaram uma ideia correta de que, para investigar, é preciso partir de uma pergunta ou de um problema, pois estes vão suscitar os alunos a pensar, levantar hipóteses, buscar respostas. Nesse sentido, concordamos com Bachelard (1996) a respeito da importância de formular problemas, visto todo conhecimento ser resposta a uma pergunta. Portanto, se não há perguntas não haverá construção de conhecimento. Complementando essa ideia, Pozo e Crespo (1998) sugerem que, se pretendemos que nossos alunos usem seus conhecimentos adquiridos na escola para resolver problemas cotidianos, devemos começar ensinando-lhes a resolver problemas.

\begin{tabular}{|l|l|}
\hline Sujeitos & Excertos \\
\hline L2 & $\begin{array}{l}\text { Eu acho que seria interessante retirar as quantidades exatas de alguns compostos a serem } \\
\text { utilizados nos experimentos (não de todos componentes). }\end{array}$ \\
\hline
\end{tabular}

Quadro 17: Categoria 5.2 - Mudando a quantidade dos reagentes.

Fonte: Elaborado pelos autores.

Entendemos essa resposta como um tanto equivocada, pois não apresenta clareza. Além do que, em muitos casos essa atitude pode ser inócua ou perigosa. Suspeitamos que o referido licenciando tenha sido influenciado por um experimento realizado no decorrer dos encontros no qual em um deles, a pesquisadora propositalmente havia adulterado uma amostra.

\begin{tabular}{|l|l|}
\hline Sujeitos & Excertos \\
\hline L4 & {$[\ldots]$, os alunos poderiam tentar reproduzir o experimento, sem o procedimento da apostila. } \\
\hline
\end{tabular}

Notamos que esse licenciando (L4), em sua resposta a questão número 2, categoria 2.5, destacou a importância de se ter um roteiro para orientar o aluno durante o experimento. Mas, naquele momento, ao pensar numa forma de tornar o experimento investigativo, acreditou que sem um procedimento ou roteiro poderia dar a possibilidade de pesquisar aos alunos. Não entendemos isso como uma boa medida em muitos casos, 
DOI: https://doi.org/10.33238/ReBECEM.2021.v.5.n.1.25879

dados os riscos que envolvem alguns experimentos, contudo, tal mudança de pensamento pode ser fruto das atividades desenvolvidas no decorrer do curso.

\section{Considerações finais}

As respostas obtidas a partir do questionário objetivando averiguar os conhecimentos dos licenciandos acerca de aspectos importantes relacionados à experimentação para o EQ, apontaram ideias empírico-indutivistas, como retratam diversas falas dos estudantes, em especial nas categorias "experimento como função de comprovar a teoria" e "visão utilitarista da ciência." No entanto, os licenciandos apresentaram também algumas percepções coerentes que consideramos razoáveis do ponto de vista da Experimentação Investigativa, tais como: valorizar os conhecimentos prévios dos estudantes antes de desenvolver um experimento em sala de aula, destacar a proposição de questões ou problemas como alternativa caso queira produzir um experimento investigativo a partir de um roteiro tradicional. Outro ponto que devemos ressaltar como importante percepção dos estudantes diz respeito ao levantamento de hipóteses durante o processo experimental.

De modo geral, percebe-se a necessidade de se abordar o conhecimento, em particular aqueles que envolvem atividade experimental, de modo mais amplo, no sentido de trazer algum aporte de caráter investigativo, reduzindo o uso dos roteiros do tipo "receita de bolo" apenas ao momento das montagens experimentais e obtenção dos resultados, promovendo um amplo debate no qual se confronte o que foi obtido com o que foi esperado, valorizando os eventuais erros e discrepâncias verificados.

Consideramos fundamental que as percepções incoerentes relacionadas ao papel da experimentação no EQ, sejam rompidas, principalmente, aquelas baseadas no modelo empirista indutivista.

Este estudo aponta para a necessidade de se ampliar discussões sobre a natureza epistemológica da experimentação em Ciências, durante a formação inicial. Essas discussões podem inclusive permear as atividades experimentais, mesmo se abordadas de modo não muito complexo. Pois, a partir das diferentes visões epistemológicas inicia-se uma crítica, por exemplo, à epistemologia de Francis Bacon. Tal conduta, certamente 
DOI: https://doi.org/10.33238/ReBECEM.2021.v.5.n.1.25879

auxiliará muitos professores a superar a visão empírico-indutivista que ainda possuem sobre a experimentação.

\section{Referências}

AZEVEDO, M. C. P. S. Ensino por investigação: problematizando as atividades em sala de aula. In: Carvalho, A. M. P. (Org.) Ensino de ciências: unindo a pesquisa e a prática. 1. ed. São Paulo: Thomson, 2013. p. 19-33.

BACHELARD, G. A formação do espírito científico. 1. ed. Rio de Janeiro: Ed. Contraponto, 1996.

BORGES, A. T. Novos rumos para o laboratório escolar de Ciências. Caderno Brasileiro de Ensino de Física, Florianópolis, v. 19, n. 3, p. 291-313, 2002.

CACHAPUZ, A. (Org.) et al. A necessária renovação do ensino das ciências. 1. ed. São Paulo: Cortez, 2005.

CAMILLO, J.; MATTOS, C. R. A experimentação no ensino de ciências: reflexões a partir da Teoria da Atividade. In: MAGALHÃES JÚNIOR, C. A. O. (Org.) et al. Ensino de ciências: múltiplas perspectivas, diferentes olhares. 1. ed. Curitiba. Editora CRV, 2014. p. 123-154.

CARVALHO, A. M. P. Ensino de Ciências: unindo a pesquisa e a prática. 1. ed. São Paulo: Cengage Learning, 2013.

ECHEVERRÍA, M. P. P.; POZO, J. I. Aprender a resolver problemas e resolver problemas para aprender. In: POZO, J. I. (Org.). A solução de problemas: aprender a resolver, resolver para aprender. 1. ed. Porto Alegre: Artmed. 1998. p. 13-42.

FERREIRA, L. H. et al. Ensino experimental de Química: uma abordagem investigativa contextualizada. Química Nova na Escola, São Paulo, v. 32, n. 2, p. 101-106, 2010.

GALIAZZI, M. C.; GONÇALVES, F. P. A natureza pedagógica da experimentação: uma pesquisa na Licenciatura em Química. Química Nova, São Paulo, v. 27, n. 2, p. 326-331, 2004.

GONÇALVES, F. P.; MARQUES, C. A. Contribuições pedagógicas e epistemológicas em textos de experimentação no ensino de química. Investigações em Ensino de Ciências, Porto Alegre, v. 11, n. 2, p. 219-238, 2006. 
DOI: https://doi.org/10.33238/ReBECEM.2021.v.5.n.1.25879

GONDIM, M. S. C.; MÓL, G. S. Experimentos investigativos em laboratório de Química fundamental. In: Encontro Nacional de Pesquisa em Educação em Ciências, 6. 2007, Florianópolis. Anais... Florianópolis: ABRAPEC, 2007, p. 1-10. Resumo 38.

HODSON, D. Experimentos em ciências e no ensino de ciências. Educational Philosophy and Theory, Auckland. v. 20, n. 2, p. 53-66, 1988.

KASSEBOEHMER, A. C. et al. Contém química 2: pensar, fazer e aprender pelo método investigativo. 1. ed. São Carlos: Pedro \& João Editores, 2015.

LÔBO, S. F. O trabalho experimental no ensino de química. Química Nova, São Paulo, v. 35, n. 2, p. 430-434, 2012.

MATOS, D. A. S; JARDILINO, J, R, L. Os conceitos de concepção, percepção, representação e crença no campo educacional: similaridades, diferenças e implicações para a pesquisa.

Educação \& Formação, Fortaleza, v. 1, n. 3, p. 20-31, set/dez, 2016.

MEDEIROS, A.; BEZERRA FILHO, S. A natureza da ciência e a instrumentação para o ensino da Física. Ciência \& Educação, Bauru: v. 6, n. 2, p.107-117, 2000.

MINAYO, M. C. S. (Org.) Pesquisa Social: teoria, método e criatividade. 1. ed. Petrópolis: Vozes, 1994.

MORAES, R.; GALIAZZI, M. C. Análise Textual Discursiva: Processo Reconstrutivo de Múltiplas Faces. Ciência \& Educação, Bauru, v. 12, n. 1, p. 117-128, 2006.

OLEQUES, L. C. et al. Reflexões acerca das diferentes visões sobre a natureza as ciência e crenças de alunos de um curso de Ciências Biológicas. Revista Eletrónica de Enseñanza de las Ciencias, v. 12, n.1, p. 10-125, 2013.

POZO, J. I.; CRESPO, M. A. G. A solução de problemas nas ciências da Natureza, In: POZO, J. I. (Org.) A solução de problemas: aprender a resolver, resolver para aprender. 1. ed. Porto Alegre: Artmed. 1998. p. 67-102.

QUEIROZ, S. L.; SOUZA, R. F.; ALEXANDRINO, D. M.. Experimentação no ensino superior de química: Análise de dissertações e teses brasileiras. X Congresso Internacional sobre investigación em didáctica de las ciencias. Enseñanza de las Ciencias, n. extraordinário, p. 1891-1895, 2017.

ROSITO, B. A. O ensino de ciências e a experimentação. In: MORAES, R. (Org.) Construtivismo e ensino de ciências: reflexões epistemológicas e metodológicas. 1. ed. Porto Alegre: EDIPUCRS, 2000. 
DOI: https://doi.org/10.33238/ReBECEM.2021.v.5.n.1.25879

SILVA, L. H. A.; ZANON, L. B. A experimentação no ensino de ciências. In: Ensino de ciências: fundamentos e abordagens. 1. ed. Campinas, R. Vieira Gráfica e Editora, 2000. p. 120153.

SOUZA, F. L, et al. Atividades experimentais investigativas no ensino de química. 1. ed. São Paulo: CETEC, 2013.

SUART, R. C.; AFONSO, S. A. Formação inicial de professores de Química: Discutindo finalidades e possibilidades sobre o papel da experimentação no ensino de química.

Experiências em Ensino de Ciências, v. 10, n. 2, p. 131-149, 2015.

SUART, R. C. A experimentação no ensino de química: conhecimentos e caminhos. In: SANTANA, E.; SILVA, E. (Org.) Tópicos em Ensino de Química. 1. ed. São Carlos: Pedro \& João Editores, 2014. p. 63-88.

Recebido em: 18 de setembro de 2020

Aceito em: 07 de abril de 2021 